\title{
Trend and Factors of Population Fertility Changes From the Perspective of Economics and Education - China, 1949-2020
}

\author{
Yiran Wang ${ }^{1,2}$; Huiyun Fan ${ }^{1,2} ;$ Chao Guo ${ }^{1,2,1}$
}

\begin{abstract}
Summary
What is already known on this topic?

Diverse social factors such as economic development, policy, culture, and special historical events could affect population fertility directly. At present, the influence of social factors on fertility is still controversial. With the diversification of population characteristics, the crossgroup robustness of the classical theories and research conclusions are broken.

\section{What is added by this report?}

This research explores the population fertility trajectory of China and its association with economy and education. Although the social fertility shows an opposite trend with the Gross Domestic Product, the economy plays a role in improving the fertility rate. The schooling years per capita inhibits the increase of fertility rate, whereas the proportion of higher education population helps to increase the fertility rate. What are the implications for public health practice?

Facing the continuous low fertility rate in the postdemographic transition period in China, promoting economic development and advancing the popularization of higher education would be important paths to create supportive and friendly social and family environments for female fertility, so as to enhance female fertility willingness and level.
\end{abstract}

As a direct result of several influencing factors, including those that are economic, political, scientific, technological, cultural, and historical, the fertility of China's population presented a trend of fluctuating decreases. This study explored the impact of economy and education on population fertility using existing literature and analysis of longitudinal data at the provincial level. This study found that the economy does play a role in improving the fertility rate although inverse development trends of gross domestic product (GDP) and crude birth rate (CBR) were found. Furthermore, schooling years per capita (PEDU) also had an inverse relationship with fertility, but the proportion of higher education population (HEDU) was positively associated with fertility. Due to urgency concerning the continuously low fertility rate in the post-demographic transition period in China, this study provides some evidence for the formulation of fertility policy in China. The results also suggest that promoting economic development and advancing the popularization of higher education are important paths to enhance female fertility willingness and fertility rates.

Data used in this study were obtained from the China Statistical Yearbooks from National Bureau of Statistics of China and from provincial-level bureaus of statistics. Based on the CBR (from 1949 to 2020) and GDP (from 1952 to 2020) of China, this study analyzed the correlation between fertility and economic activity nationwide. The GDP and CBR trends at the regional level (the eastern, central, western, and northeastern region, divided by the overall national levels provided by the National Bureau of Statistics of China*) were further described. Then, a panel database of 31 provincial-level administrative divisions (PLADs) of China from 2002 to 2019 was constructed with indicators of CBR (\%), GDP (100 billion CNY), PEDU (year), and HEDU (\%), sex ratio (female=100), urban population density $\left(100\right.$ persons $\left./ \mathrm{km}^{2}\right)$, urbanization rate $(\%)$, urban registered unemployment rate $(\%)$, old-age dependency ratio (\%), labor proportion (total population=1), and average family household size (persons).

Based on the panel data, a fixed-effects model was used for regression analysis with CBR as the predicted

\footnotetext{
* The National Bureau of Statistics of China divides 31 PLADs in mainland China into 4 major regions: the eastern, central, western, and northeastern regions. The eastern region includes Beijing, Tianjin, Hebei, Shanghai, Jiangsu, Zhejiang, Fujian, Shandong, Guangdong, and Hainan; the central region includes Shanxi, Anhui, Jiangxi, Henan, Hubei, and Hunan; the western region includes Neimenggu, Guangxi, Chongqing, Sichuan, Guizhou, Yunnan, Xizang, Shaanxi, Gansu, Qinghai, Ningxia, and Xinjiang; the northeastern region includes Liaoning, Jilin, and Heilongjiang.
} 
variable, GDP, and PEDU and HEDU as explanatory variables, and other indicators mentioned above as control variables. Stata 13.0 (developed by StataCorp LLC, Texas, USA) was used for all the data analysis.

Figure 1 presents long-term changes in the economy and fertility. At the national level, Chinese CBR decreased overall from 1949 to 2020, which is inverse to the overall increase in GDP. From a regional perspective (Figure 2), the CBR of the four regions also presented an inverse-economic distribution pattern since 1949. However, the northeastern region displayed a both decreased economic activity and decreased fertility over this time period since 2014 .

Table 1 shows the results of the association of fertility with economic activity and education from the regression analysis. Based on the fixed-effects model, it was found that after controlling for multiple covariates, a significant positive impact of GDP on CBR was found (coefficient $=0.045, P<0.001$ ). In addition, we found a negative impact of PEDU on CBR (coefficient $=-0.945, \quad P<0.001$ ), but a significant positive impact of HEDU on CBR (coefficient $=0.085$, $P=0.004)$. The Hausman test was conducted and the results suggested using the fixed-effects model. The multi-collinearity of the 10 variables in the regression was also tested and found that the variance inflation factors of them were all less than 10 (Supplementary Table S1, available in http://weekly.chinacdc.cn/), meaning that there was no multi-collinearity among the variables in the model.

\section{DISCUSSION}

This study provided evidence of declining fertility rates to be correlated to increased economic activity in China, which was consistent with common trends between a country's economy and population fertility over a long period of time. However, the northeastern region had both low fertility and low economic activity since 2014, which may be due to comprehensive and systemic issues such as regional economic systems, industrial structures, and social policies that led to population loss and decreased fertility willingness, etc. (1). Western demographic transition theory often described a close connection between population size and means of subsistence (2), and there were no limitations on population fertility in an era of extremely low productivity. However, with continuous development of productivity, the economy begins to affect fertility by acting on intermediary variables such

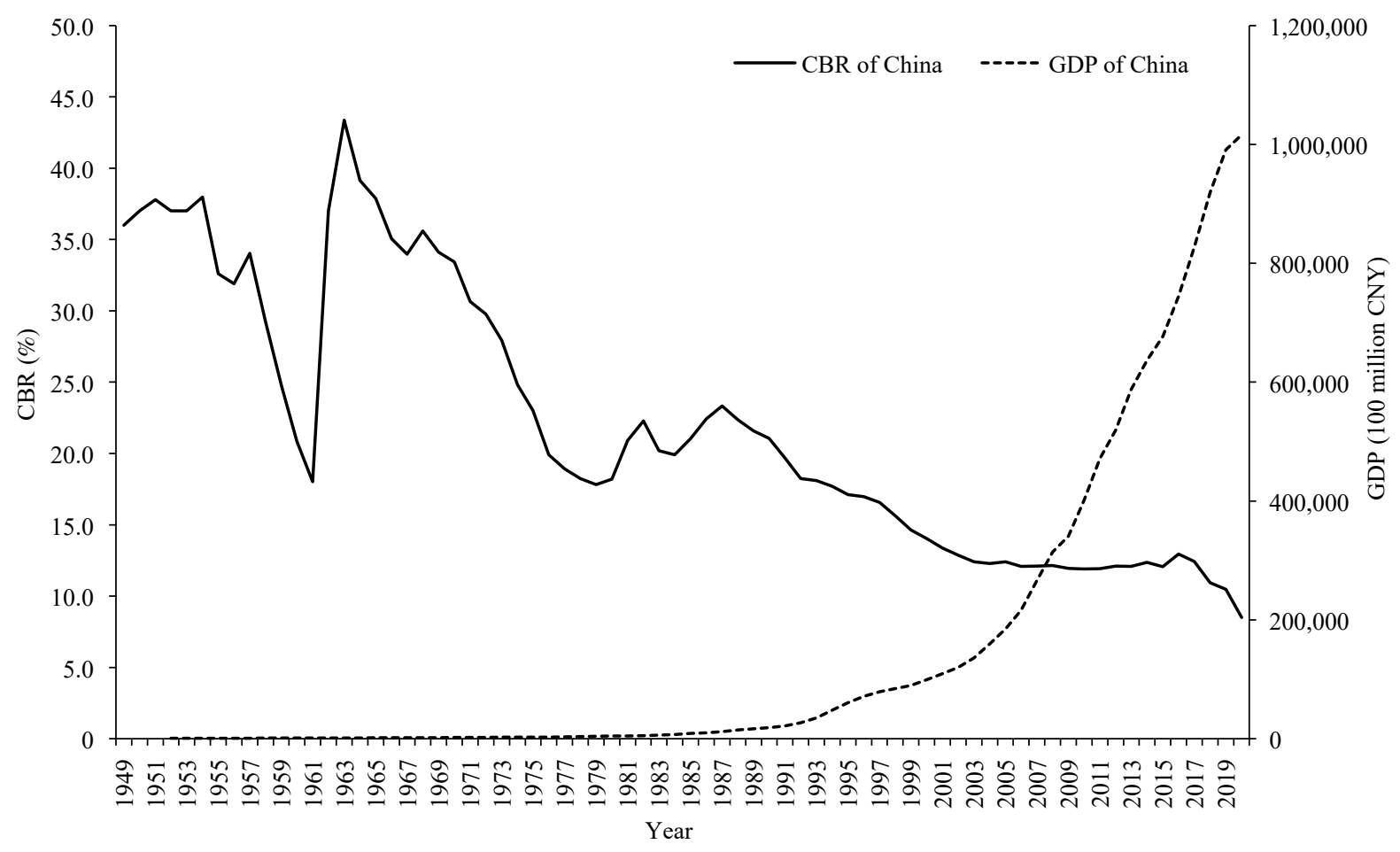

FIGURE 1. Changes of CBR of China (1949-2020) and GDP of China (1952-2020).

Source: the National Bureau of Statistics of China.

Abbreviations: $\mathrm{CBR}=$ crude birth rate, GDP=gross domestic product. 


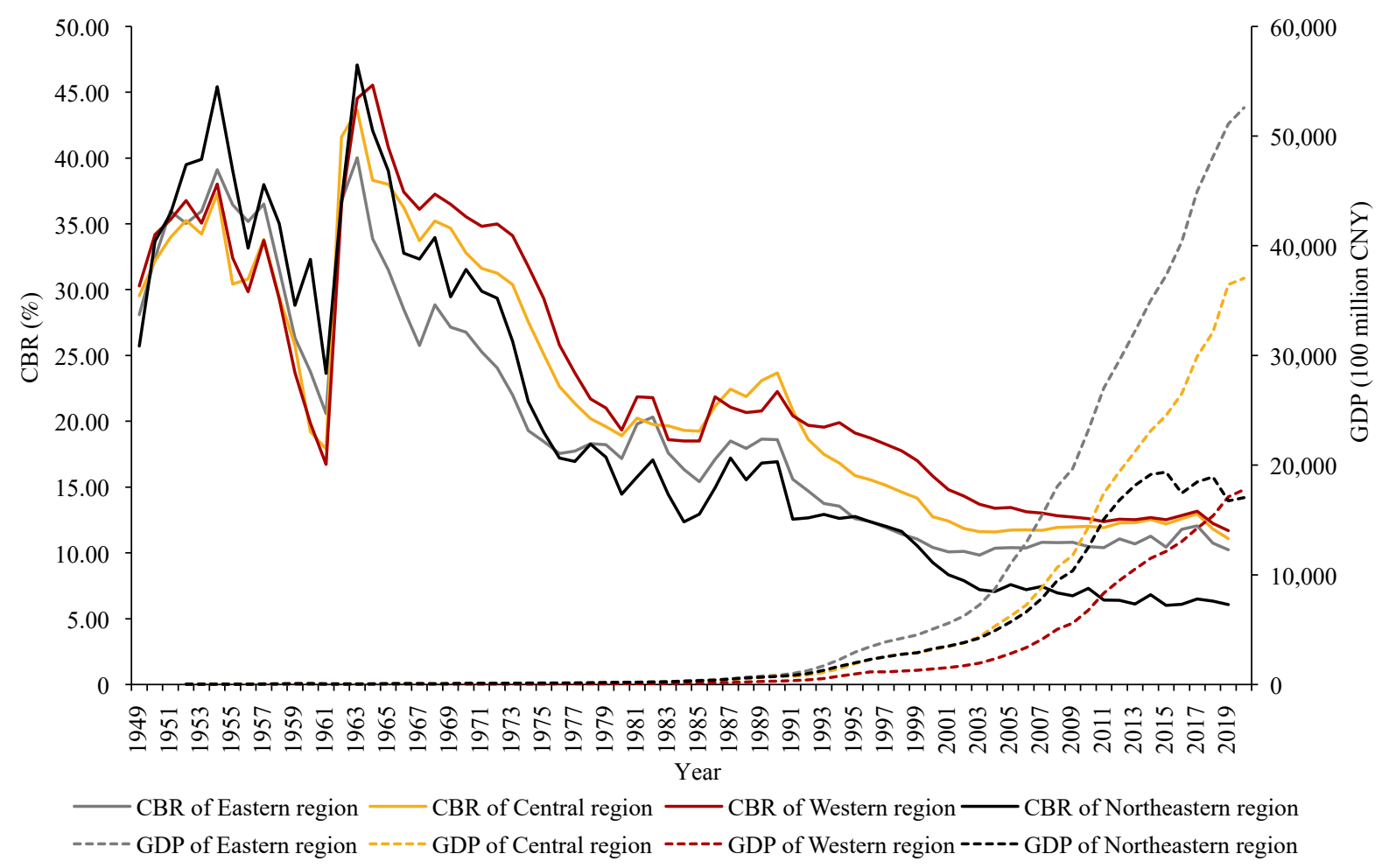

FIGURE 2. Changes of CBR of 4 regions in China (1949-2019) and GDP of 4 regions in China (1952-2020). Source: the National Bureau of Statistics of China.

Abbreviations: $\mathrm{CBR}=$ crude birth rate, $\mathrm{GDP}=$ gross domestic product.

TABLE 1. The association between economy and education with CBR: results of fixed-effects model $(n=533)$ in China, 2002-2019.

\begin{tabular}{cccccc}
\hline Variables & Coef & Std. Err & t & $\boldsymbol{P}$ & $\mathbf{9 5 \%} \mathbf{C l}$ \\
\hline GDP & 0.045 & 0.006 & 6.94 & $<0.001$ & 0.032 to 0.057 \\
PEDU & -0.945 & 0.253 & -3.74 & $<0.001$ & -1.442 to -0.449 \\
HEDU & 0.085 & 0.029 & 2.91 & 0.004 & 0.027 to 0.142 \\
Sex ratio & -0.037 & 0.015 & -2.49 & 0.013 & -0.066 to -0.008 \\
Old-age dependency ratio & -0.083 & 0.030 & -2.81 & 0.005 & -0.141 to -0.025 \\
Labor proportion & 0.387 & 3.411 & 0.11 & 0.910 & -6.315 to 7.089 \\
Average household size & 0.795 & 0.310 & 2.56 & 0.011 & 0.185 to 1.405 \\
Urban population density & -0.013 & 0.006 & -2.32 & 0.021 & -0.024 to -0.002 \\
Urbanization rate & 0.016 & 0.013 & 1.26 & 0.207 & -0.009 to 0.042 \\
Urban registeredUnemployment rate & 0.175 & 0.124 & 1.41 & 0.160 & -0.069 to 0.419
\end{tabular}

Abbreviations: PLADs=provincial-level administrative divisions, CBR=crude birth rate, GDP=gross domestic product, $\mathrm{PEDU}=\mathrm{schooling}$ years per capita, HEDU=proportion of higher education population, Coef=regression coefficient, Std. Err=standard error, $\mathrm{Cl}=\mathrm{confidence}$ interval.

as through marriage rates, education, medical and health services, etc. (2).

Notably, it is found that the economy does play a role in improving the fertility rate after multiple covariates was adjusted. GDP is a macroeconomic indicator, and there are multiple ways in which it may affect the population fertility. Possible reasons for the positive association between the two could include the following: 1) economic development improves the ability of couples of childbearing age to raise children and provides more security for more children; 2) economic development generally improves education, which may strengthen gender equality and better distribute the child-raising responsibility across husbands and wives to enhance incentives for women to have children; and 3) there is "CBR offset" among 
regions, which means the compensations and balances between different fertility rates of different regions. For example, the urban-rural divide in China affects fertility as urban economic development stimulates the increase of fertility rate, but rural economic development reduces it (3).

In terms of the impact of education on fertility, we found that the PEDU inhibited the increase of CBR but that HEDU helped to improve the CBR. It is generally believed that the increase in education level for women has largely contributed to the decline in fertility (4-5). Education has tended to be correlated with reduced fertility since early in the 20th century when this phenomenon was first observed (G). Theories about fertility costs and benefits help explain this suppression mechanism, that is, as the education level of couples of childbearing age increases, the number of children tends to be reduced as the resources available to each child increases (1). However, after subdividing according to the population characteristics, the conclusions show differences. Couples with the highest and the lowest education levels tended to be more willing to have children ( 7 ).

Compared with the aforementioned individual research perspective, this study found the negative effects of the schooling years per capita on the fertility rate and a positive effect of the popularization rate of higher education on the fertility rate for the overall population. This suggested that overall education level of the population had a segmented effect on the fertility rate. Theoretical explanations and research conclusions from the individual perspective above provide inspiration for this study to explore the impact mechanisms of education on fertility from a macro perspective. Generally speaking, an increase in the education level of the group is correlated by an improvement of the economy, accompanied by increased market competition and crowded development channels. Compared with social development stages when a population is at lower education levels, this kind of competitive development environment has increased the opportunity cost of childbirth as well as childbirth pressure, leading to declines in women's fertility willingness. However, this phenomenon of "educational fertility suppression" began to disappear with further increases of the education level of the population. This may be attributed to popularization of higher education which represents further development of the economy and society as well as increasingly abundant resources. Under these conditions of societal development, higher education groups take the lead in breaking through restraints of limited resources. They are more likely to have equitable husband and wife relationships (8), abundant income, and diversified social security resources. These guarantee mechanisms provide women of childbearing age with more reproductive security as the costs and risks of childbirth are diminished. Further promoting the popularization of higher education and raising the overall education level of the population is a policy direction for improving the population fertility level.

At present, China is facing sustained decreases in fertility. The fertility regulation policy has evolved from "double-single two-child policy" (where couples may have a second child if both parents were the only children to their parents) to the universal "three-child" in just 10 years. This shows the government's determination in increasing the population fertility level. Handling the relationship between population fertility and social factors is essential for scientifically formulating fertility strategies and optimizing the population structure in China. Low fertility is an important cause of population aging in China, which may incur a heavy disease burden of large-scale noncommunicable diseases, injuries, and disabilities that may cause tremendous pressure on population health protection systems. Therefore, grasping the relationship between multiple social factors and population fertility and implementing long-term strategies of optimizing population age distributions are important tasks for the construction of population health protection systems in China.

The study was subject to some limitations. First, the influencing factors of fertility rate are complex and uncertain, so confounding factors in this exploratory study need to be examined further. Second, the sample size of this study is relatively small due to the use of provincial-level data even after the time scale of the study was expanded to the limits of the data. We suggest that future studies expand to using county-level data to verify the results of this study.

Nevertheless, based on the current research results, in the face of continued low fertility in the postdemographic transition period in China, promoting economic development and advancing the popularization of higher education are important paths to create supportive and friendly social and family environments to improve willingness and overall 
fertility.

Funding: The Scientific Research Foundation of Peking University (No.7100603492 and No.7100 901906).

doi: $10.46234 / \mathrm{ccdcw} 2021.159$

\# Corresponding author: Chao Guo, chaoguo@pku.edu.cn.

${ }^{1}$ Institute of Population Research, Peking University, Beijing, China; ${ }^{2}$ APEC Health Science Academy (HeSAY), Peking University, Beijing, China.

Submitted: June 12, 2021; Accepted: June 28, 2021

\section{REFERENCES}

1. National Health Commission of the People's Republic of China replied to solve the problem of population decline in Northeastern region in China. http://henan.china.com.cn/tech/2021-02/19/content_41471693. htm. [2021-7-6]. (In Chinese).

2. Li JN. Modern western population theory. Shanghai: Fudan University
Press. 2004. (In Chinese).

3. Peng HR, Meng X. China's decline of birth rate and economic development. Stat Res 2014;31(9):44-50. https://d.wanfangdata.com. cn/periodical/ChlQZXJpb2RpY2FsQ0hJTmV3UzIwMjEwNjE2EhB0b 25nanlqMjAxNDA5MDA3GghvMjdmcHJreg\%3D\%3D. (In Chinese).

4. Rindfuss RR, Morgan SP, Offutt K. Education and the changing age pattern of American fertility: 1963-1989. Demography 1996;33(3):27790. https://link.springer.com/article/10.2307/2061761.

5. Dorvlo ASS, Bakheit CS, Al-Riyami A, Morsi M, Al-Adawi S. A study of fertility patterns of ever married women in Oman. Sultan Qaboos Univ Med J 2006;6(2):33-40. https://www.ncbi.nlm.nih.gov/pmc/articles/ PMC3074913/.

6. Skirbekk V. Fertility trends by social status. Demogr Res 2008;18:14580. https://www.demographic-research.org/volumes/vol18/5/.

7. Zhao MH. Fertility intentions for a second child in China: female educational attainment and assortative marriage. Popul J 2019;41(3): 1627. https://kns.cnki.net/KCMS/detail/detail.aspx?dbcode=CJFQ \&db name $=$ CJFDLAST2019\&filename $=$ RKXK201903002\&v $=$ Mjc3NjhZT 1 pvRnl6bFU3dk9OeWJUWmJHNEg5ak1ySTIGWm9SOGVYMUx1eFl TN0RoMVQzcVRyV00xRnJDVVI3dWY=. (In Chinese).

8. Cherlin AJ. A happy ending to a half-century of family change? Popul Dev Rev 2016;42(1):121 - 9. http://dx.doi.org/10.1111/j.1728-4457. 2016.00111.x. 
China CDC Weekly

SUPPLEMENTARY TABLE S1. Test results of multi-collinearity of 10 variables.

\begin{tabular}{|c|c|c|}
\hline Variables & VIF & $1 /$ VIF \\
\hline GDP & 1.60 & 0.626 \\
\hline PEDU & 6.14 & 0.163 \\
\hline HEDU & 4.96 & 0.201 \\
\hline Sex ratio & 1.26 & 0.794 \\
\hline Old-age dependency ratio & 3.06 & 0.327 \\
\hline Labor proportion & 3.82 & 0.262 \\
\hline Average household size & 4.08 & 0.245 \\
\hline Urban population density & 1.14 & 0.876 \\
\hline Urbanization rate & 6.51 & 0.154 \\
\hline Urban registered unemployment rate & 1.62 & 0.616 \\
\hline
\end{tabular}

Abbreviations: GDP=gross domestic product, PEDU=schooling years per capita, HEDU=proportion of higher education population, $\mathrm{VIF}=$ variance inflation factor. 